\title{
An Important Way for the Balanced Development of China's Higher Education: First-class Universities to the Central and Western Regions
}

\author{
Xueqian Zhang \\ School of Public Affairs, University of Science and Technology of China, 96 Jin Zhai Road, Hefei 230000, \\ Anhui Province, China
}

\begin{abstract}
With the support of the higher education institutions in the western region and the promotion of the higher education revitalization plan in the central and western regions, China has basically solved the problem of "higher education poverty in the central and western regions", but the relationship between supply and demand of high quality higher education is still very tense, especially in the central and western high quality higher education. Being lack of resources and a small number of first-class universities, the uneven geographical distribution of high-quality higher education resources has become the main factor restricting the overall development of China's higher education. How to rationally allocate high-quality higher education resources in the east to the central and western regions, the feasibility of first-class universities to the central and western schools, and the promotion of policies to solve the central and western are of great significance.
\end{abstract}

Keywords: higher education balance, first-class university, central and western school

DOI: $10.7176 / \mathrm{JEP} / 10-9-06$

Publication date:March $31^{\text {st }} 2019$

\section{Introduction}

Since the new century, China has promoted higher education in the central and western regions to a new level by implementing major measures such as counterpart support and targeted enrollment programs in the western region. However, due to various reasons such as history, economy and geography, the level of education development in the central and western regions is still relatively lagging behind. The foundation of higher education is poor, and the ability to serve economic and social development is weak, especially in the provinces of Tibet, Qinghai and Ningxia, which is difficult to meet the needs of the people to accept high-quality higher education, and it is difficult to adapt to the needs of high-level talents for economic and social development.

The Outline of the China Medium- and Long-Term Education Reform and Development Plan (2010-2020) clearly states that promoting fairness is a basic national education policy, rational allocation of educational resources, and accelerating the narrowing of the educational gap. Since 1999, the reform of China's higher education popularization has continued to advance, and the transformation from "elite" to "popularization" has been realized. A large country of higher education has been established, however, while achieving this great achievement, there are also some problems: on the one hand, the overall supply of educational resources, especially high-quality resources, is insufficient; on the other hand, the regional allocation of high-quality higher education resources is uneven. As a representative high-quality resource, a first-class university carrying out its national layout research will be of great significance to promoting China's entry into a higher education power.

\section{The significance of first-class universities to run schools in the central and western regions}

2.1 Improve the level of higher education and accelerate the construction of a strong country in higher education In February 2017, the Ministry of Education held a promotion meeting for the implementation of the Central and Western Higher Education Revitalization Plan. The meeting pointed out that the essence of revitalizing higher education in the central and western regions is common development, common improvement, and common progress (MOE, 2017). In the actual allocation of high-quality higher education resources in China, there are 14 domestic first-class universities (formerly 985 colleges) in the central and western regions, and 47 national key universities (formerly 211 colleges), accounting for $36 \%$ and $40 \%$ of the national total, respectively. The layout of domestic first-class universities in 13 provinces including Shanxi, Inner Mongolia, Jiangxi, Henan, Guangxi, Hainan, Guizhou, Yunnan, Tibet, Qinghai, Ningxia and Xinjiang is still in a blank state. However, the land and population in the central and western regions exceed the national two-thirds and one-half respectively. This shows that the problem of unreasonable regional distribution of high-quality higher education resources is very serious. The ability of first-class universities to run schools in the central and western regions provides a possibility for the redistribution of high-quality higher education resources. This is not only useful for narrowing the gap between the inferior education and the developed provinces, but also for improving the level of higher education in the central and western regions. The common development of education and the realization of educational equity have a positive impact, and thus promote the construction of a strong country in higher education. 
2.2 Cultivating advanced production factors and boosting economic development in the central and western regions

What do you need for the development of the Midwest? What do you need for higher education in the Midwest? Undoubtedly, top talents, abundant funds, and preferential policies are needed. It is necessary to "feed blood transfusions", but what is more needed is to enhance their own "hematopoietic function". This hematopoietic function means self-construction and training of talents and independent expansion of funding sources. First-class universities have a typical leading role. American economist Paul A. Samuelson pointed out that modern economic growth includes four elements: human resources, natural resources, capital accumulation, technological change and innovation, among which human resources, technological change and innovation are closely related to higher education. Therefore, high-quality higher education resources, especially first-class universities, have a significant role in promoting regional economic development. The performance is as follows: First, first-class universities can train top talents needed for regional economic development. In the era of knowledge economy, top talents are the decisive factor for economic development. Second, first-class universities can bring technological support to regional economic development. Economic development relies on advanced technologies. Local enterprises can share their latest scientific research results through cooperation with universities. In turn, the scientific research results are transformed into productivity that promotes economic development. Third, first-class universities directly promote regional economic development. For example, the construction of universities provides employment opportunities for local residents, and the teachers and students expand the regional consumer market (Qiu Junping, 2010). When the country is planning the construction of first-class universities and first-class disciplines, we must consider the important factors of geographical distribution, focus on the long-term development of the central and western regions, and encourage first-class universities to run schools in the central and western regions. Candidates can enter the first-class universities without going out of the province. To cultivate the "high quality, retain, and use" talents for the central and western regions, and promote the economic development of the central and western regions.

\subsection{Expanding the space for education to alleviate poverty and building a well-off society in an all-round way} As a representative of high-quality education resources, first-class universities have a wide range of radiant functions and can expand the space for education to alleviate poverty. First, to promote the development of local characteristic industries, first-class universities have the advantages of science and technology, can provide toplevel design for industrial development in poverty-stricken areas, and formulate industrial development plans in line with local realities. Second, first-class universities are the gathering and distributing places of new ideas, which provide a basis for organizing and developing specialized training of professionals. Thirdly, it helps to promote the construction of spiritual civilization, the first-class universities have many advantages such as student unions and alumni associations, who help the poor people to establish modern civilization concepts and change backward customs (MOE, 2016).

Governing poverty and treating ignorance will help the poor. The foundation of "governing fools" and "supporting wisdom" lies in the development of education. Compared with economic poverty alleviation and policy poverty alleviation, education poverty alleviation directly refers to the root cause of poverty and backwardness. To make up for the "short board" of education is to solve the problem of uneven distribution of educational resources in the eastern and central and western regions. The first-class university to the Central and Western China not only promotes the rational allocation of educational resources, but also attracts more top talents to participate in the education of the central and western regions, and promotes the victory of the central and western regions to fight poverty and lay a solid foundation for building a well-off society in an all-round way.

\section{The feasibility of running a first-class university to the central and western regions}

3.1 The central government policy has provided support for the first-class university in the west

The Chinese government has always attached importance to the development of higher education in the central and western regions, and has formulated and implemented a series of related policies to provide a strong support for first-class universities to run schools in the central and western regions. In 2013, the Ministry of Education, the National Development and Reform Commission and the Ministry of Finance issued the "Central and Western Higher Education Revitalization Plan (2012-2020)". Aiming at the problems of "the number of national high-level universities and key disciplines is too small, and the setting of disciplines is not reasonable" in the central and Western regions, the paper clearly proposed to optimize the layout structure of the central and western institutions, strengthen the construction of disciplines in the central and western, and expand the opportunities for students in the central and western regions (MOE, 2013). In 2016, the General Office of the State Council issued the "Guiding Opinions of the General Office of the State Council on Accelerating the Development of Education in the Central and Western Regions", which focused on improving the development level of higher education in the central and western regions, and encouraged many parties to jointly build colleges with distinctive industries and improve the ministries and ministries. The committee and the ministries and municipalities have given strong support to the 
joint construction model (GOSC, 2016). In 2017, the State Council issued the "13th Five-Year Plan for National Education Development", emphasizing the optimization of the regional distribution of educational resources, supporting the increase of quality education resources in the central and western regions, improving the regional educational cooperation mechanism, and encouraging the distribution of higher education resources and industries from east to west. The gradient transfer is linked to enhance the comprehensive strength of education development in the central and western regions, and further narrow the gap with the developed regions in the east (TSC, 2017). Higher education is an important support for regional economic and social development and a strategic measure to enhance urban competitiveness. The provinces in the central and western regions pay special attention to the introduction of high-quality higher education resources. In 2015, Guangxi province issued the "Opinions on Deepening the Comprehensive Reform of Higher Education" and proposed to "intensify efforts to introduce highquality educational resources at home and abroad, and vigorously support the cooperation between universities and high-level universities at home and abroad" to deepen the opening up of higher education(PGGZAR ,2015). Guizhou province issued the "Opinions on Promoting the Opening of Foreign Exchanges and Cooperation among Colleges and Universities (Trial)", pointing out that it is necessary to attract well-known schools, education and scientific research institutions from home and abroad to set up higher education teaching, training, research institutions or projects in our province. Improve the overall level of higher education in our province and promote economic and social development (GPDE, 2011). Zhang Jianren, deputy director of the Education Department of Xinjiang Autonomous Region, issued a paper "Some Thoughts on the Development of Higher Education in Xinjiang", and put forward the strategic concept of Xinjiang's higher education development, including actively introducing famous key universities to hold secondary colleges in the region and introducing high-quality educational resources in the Mainland (Zhang Jianren, 2006).

\subsection{The development potential of the central and western regions provides space for the first-class university to move westward}

The Midwest provides specific resources for the construction of first-class universities. When first-class universities serve the region, these regions will also provide rich support resources. In essence, all the resources of a university are derived from other subjects. For the first-class universities, the decoupling from the industry management departments will gradually make the way to obtain resources from the industry dimension disappear, and the school in the central and western regions is more conducive to opening up new ones.

The Midwest provides a platform for the functioning of first-class universities. On the one hand, the rapid development of the central and western economy can absorb the talents cultivated by first-class universities, and the faster the economy develops, the more obvious this absorption effect is, because the graduates have a good employment situation and broad prospects; on the other hand, the economy development provides a platform for the transformation of scientific research achievements of first-class universities, and at the same time promotes regional economic development and enables the university's social service functions to be exerted (Qiu Xiang ,2011).

The development of the central and western regions will have a positive impact on the discipline layout and professional settings of first-class universities. For example, in the primary industry, the central and western regions have advantageous industries such as agriculture and forestry. First-class universities can add disciplines such as ecology and drought, pollution-free agriculture, etc. The first-class agricultural universities will have more possibilities in running schools in the west. Second, the western region is rich in mineral resources and has the natural advantages of resource development and processing industries. The first-class universities of science and engineering will serve the regional development more directly in the central and western regions. In the tertiary industry, the central and western regions have many characteristic human resources, such as Tibetan culture, minority culture, etc., the first-class liberal arts universities can add disciplines such as ethnology, and open up new economic growth points for the central and western regions.

\subsection{There are precedents in China: Hefei Campus of Beijing University of Aeronautics and Astronautics}

In 2015, National Leader Xi Jinping at the National Science and Technology Innovation Conference put forward that "scientific research should not only pursue knowledge and truth, but also serve economic and social development and the broad masses of the people. The vast number of scientific and technological workers must write their thesis on the land of the motherland. The application of scientific and technological achievements is in the great cause of modernization." In 2016, Beijing University of Aeronautics and Astronautics and Anhui Provincial People's Government signed a comprehensive strategic cooperation agreement in Hefei City to jointly build Hefei Science City of Beijing University of Aeronautics and Astronautics, aiming at scientific research and innovation and transformation of achievements. In the field of higher education, we will carry out multidisciplinary and all-round cooperation, and establish a school-collaborative collaborative innovation system combining government, industry, and research.

The mission of BUAA to Hefei is the common aspiration of both sides. It expands the space and pattern of 
running schools in BUAA, strengthens the supply of Hefei technology, and serves the economic and social development of the central region. It is an important way to explore the road of first-class university construction with Chinese characteristics. The specific measures of the national strategy such as "The Belt and Road Initiative" and "Yangtze Economic Belt" are vivid manifestations of the mission of "writing the paper on the land of the motherland" and set a model for school-to-ground cooperation for first-class universities to run schools in the central and western regions.

\section{The policy recommendations of first-class universities to run schools in the central and western regions}

4.1 Relevant ministries and commissions strengthen policy support and improve the support system for running schools in western universities

Regulate structural shortages and strengthen the government's role in the allocation of quality higher education resources. The structural shortage of higher education resources is mainly reflected in the annual budget between key universities and ordinary universities, between developed regions and underdeveloped regions. For example, as the same first-class universities, there are as high as 23.335 billion RMB, some only 3.113 billion RMB; among the inter-regional per capita education funds (2015 ordinary higher education institutions), Beijing's per capita education expenditure is 32,147.32 RMB, and Sichuan's is 5,427.63 RMB.

Resolving structural shortages requires a series of institutional changes and policy adjustments. It is recommended that the measures taken at this stage include: (1) increasing investment in higher education in the central and western regions; (2) determining the per capita funding standard, in the form of legislation or clear institutional requirements to ensure the investment in the universities in the central and western regions; and (3) improving the fiscal transfer payment system of the central and provincial governments, increasing the financial transfer payments to the central and western regions, and being clear the proportion of financial transfer payments for higher education; (4)the state has introduced a plan to encourage first-class universities to run schools in the central and western regions, and formulate incentive policies for schools from the eastern universities to the central and western regions, such as scientific research projects and special high-level talent programs.

\subsection{Local governments strengthen support and connection with first-class universities in the central and western regions}

Formulate the land use policy for first-class universities in the central and western regions, improve the overall land use planning, clearly stipulate that new construction land should be used preferentially for higher education development; Subsidies should be given to teachers who come to work in the region, and preferential policies for teachers to buy houses should be improved in order to attract excellent teachers.

Improve the employment and entrepreneurial environment and promote the local employment of outstanding graduates. In order to retain outstanding talents, it is recommended that the local government formulate a series of preferential policies and treatments for graduates who intend to stay in the local work. For example, in terms of wages and salaries, a considerable amount of home security fees will be paid at one time, and those who have worked for a certain number of years in underdeveloped areas have given policy inclinations in recruiting civil servants.

\subsection{First-class universities share resource service regional development, adhere to the docking of superior disciplines and regional pillar industries}

Sharing high-quality resources and building a higher education resource system for first-class universities in the central and western regions. In the case of shortage of resources in the central and western regions, how to steadily improve its quality has become an urgent issue, and the establishment of high-quality resources by domestic firstclass universities to the central and western regions has become an effective way to solve this problem, includes the following two aspects: (1) Sharing of human resources, the first-class university to the Central and Western China will accelerate the pace of popularization of high-quality higher education. It is recommended that all campuses of first-class universities should employ teachers in a unified manner, encourage teachers to work in the central and western campuses, or take positions in the central and western regions according to the disciplines, and promote high-level teachers move to the central and western regions, bringing more high-level talents to the central and western regions; (2) sharing material resources, using modern information technology and network technology to establish an information sharing platform across campuses, breaking geographical restrictions and realizing information sharing.

\section{References}

General Office of the State Council. Guidance of the General Office of the State Council on Accelerating the Development of Education in the Midwest [EB/OL]. http:/www.gov.cn/zhengce/content/201606/15/content 5082382.htm, 2016-6-15.

Guizhou Provincial Department of Education. Notice of the Guizhou Provincial Department of Education on the 
Opinions of the Guizhou Provincial Department of Education on Promoting the Opening of Colleges and Universities to Expand Foreign Exchanges and Cooperation (Draft for Comment) [EB/OL]. http://www.gzsjyt.gov.cn/zwgk/xxgkml/zcwj/qjh/201712/t20171206_2932910.html, 2011-5-11.

Ministry of Education. Accelerate the reform of the development of higher education in the central and western regions. The promotion meeting for the implementation of the Central and Western Higher Education Revitalization Plan will be [EB/OL]. http://www.moe.edu.cn/jyb_xwfb/gzdt_gzdt/moe_1485/201702/t20170224_297305.html, 2017-02-24.

Ministry of Education, National Development and Reform Commission and Ministry of Finance. Notice on Printing and Distributing the Central and Western Higher Education Revitalization Plan (2012-2020) [EB/OL]. http://old.moe.gov.cn//publicfiles/business/htmlfiles/moe/s7056/201303/148468.html, 2013-2-20.

People's Government of Guangxi Zhuang Autonomous Region. The opinions of the People's Government of Guangxi Zhuang Autonomous Region on deepening the comprehensive reform of higher education (Gui Zheng Fa [2015] No. 6) [EB/OL]. http://www.gxzf.gov.cn/html /37918/20150228-440061.shtml, 2015-0228.

Qiu Junping, Wen Fangfang. Research on the Regional Distribution of China's Higher Education ResourcesBased on the Empirical Analysis of the Evaluation Results of Chinese Universities and Disciplines in 2010[J]. China Higher Education Research, 2010, (07): 17-21.

Qiu Xiang. Research on the interaction mode between Chinese industry-specific universities and regional economy [D]. Beijing University of Posts and Telecommunications, 2011.

The Ministry of Education and other six departments. The Ministry of Education and other six departments issued a notice on the "13th Five-Year Plan for Education for Poverty Alleviation" [EB/OL]. http://www.moe.edu.cn/srcsite/A03/moe_1892/moe_630/201612/t20161229_293351.html, 2016-12-27.

The State Council. Notice of the State Council on Printing and Distributing the 13th Five-Year Plan for the Development of National Education [EB/OL]. http://www.gov.cn/zhengce/content/201701/19/content 5161341.htm, 2017-1-19.

Zhang Jianren. Some Thoughts on the Development of Higher Education in Xinjiang[J]. Journal of Educational Development, 2006, (01): 50-54.

I was born Jining city in china 1990. I completed my First Degree in Project Management at Qingdao Technological University in Qingdao Shandong China 2013, before joined for my Doctorate Degree at University of Science and Technology of China in Hefei Anhui Province. Now my major is public administration, and my research direction is education policy, at University of Science and Technology of China. 